\title{
Design of a Variable Frequency and Energy Aeroengine Ignition Device Based on MCU
}

\author{
Xuan Wang $\mathbb{1 D}^{1,2}$ \\ ${ }^{1}$ AECC Harbin Dong'an Engine Co. Ltd., Harbin 150069, China \\ ${ }^{2}$ College of Mechanical and Electrical Engineering, Northeast Forestry University, Harbin 150006, China \\ Correspondence should be addressed to Xuan Wang; wangxuan@nefu.edu.cn
}

Received 18 December 2021; Revised 1 January 2022; Accepted 3 January 2022; Published 28 January 2022

Academic Editor: Tongguang $\mathrm{Ni}$

Copyright (C) 2022 Xuan Wang. This is an open access article distributed under the Creative Commons Attribution License, which permits unrestricted use, distribution, and reproduction in any medium, provided the original work is properly cited.

\begin{abstract}
That the aeroengine ignition device's ignition properties are set as a rule of thumb causes the waste of ignition device's resources, low efficiency of aeroengine's operation, and short service life of plugs. In this paper, a variable frequency and energy aeroengine ignition device is developed for improving aeroengine combustion chamber's ignition properties. The STC89C52 MCU was chosen as the device's core controller. Power supply circuit, MCU and external circuit, IGBT drive circuit, boost circuit, currentvoltage monitor circuit, and discharge circuit are all part of the hardware circuit. Because the MCU is in charge of driving the IGBT and discharging the capacitor, the device can accurately generate a corresponding frequency output signal. It also creates frequency control and energy control modules, both of which can adjust ignition properties according to user needs. The ignition device proposed in this paper is stable and lighter and has a predetermined frequency and energy. It lays the groundwork for improving the aeroengine's ignition reliability.
\end{abstract}

\section{Introduction}

\subsection{Research Status}

1.1.1. Research Actuality. At present, many domestic ignition devices adopt reverse flyback converters to boost the voltage [1-3]. They use a gas discharge tube to discharge electricity. A few advanced ignition devices use MOSFET to boost the voltage [4-6]. That some western countries have begun to develop electronic ignition devices, which are small and light, and have precision frequency, laying a perfect foundation for the subsequent study of variable frequency and energy ignition devices.

The performance of domestic high-temperature semiconductors is very low, which cannot follow the desire of requesting large aeroengine high-temperature working environment [7, 8]. At present, domestic large aeroengine ignition device mainly uses a mechanical resonance inverter booster transformer to succeed inverter booster. It adopts gas discharge tubes as discharging control switches $[9,10]$. Only some small engines, power plants, and starters which require low-temperature working environment use semiconductor power tube boost circuit [11].

1.1.2. Trend. Aeroengine fuel must be ignited by an ignition system and burned, which serves as a source of energy. Engines must have a low rate of controlling in-flight shutdown and good in-flight ignition capability. The ignition system $[12,13]$ is a critical component of the engine's starting and restarting process, and its operating characteristics and abilities have a direct impact on whether engines start and restart successfully, as well as the engine's overall safety. The following is a summary of the future development trend of domestic aeroengine ignition systems:

(1) From inductive energy storage to capacitor energy storage ignition device: the ignition device, which has a special energy storage device inside, is a key component of energy storage and release. The stored energy of an inductive energy storage ignition device is typically several dozens of millijoules, with high and uncontrollable discharge frequencies. The stored 
energy of a capacitor energy storage ignition device can be several dozens of joules, with low and controllable discharge frequencies. The inductive energy storage system's stored energy is used for indirect ignition, which is heavy. The capacitor energy storage system's stored energy is used for direct ignition. Unless an old machine type is isolated, new machine types now use a capacitor ignition system rather than an inductive system. By controlling the energy-storing capacitance charge, the capacitance discharge ignition system accumulates enough voltages. It releases energy into the ignition spark plug by capacitance discharging instantaneously [14].

(2) From mechanical to electronic ignition device: The development of the ignition system is also the development of electronic components. Contact ignition device grows into contactless ignition device. And analog ignition device grows into digital ignition device.

The main difference between a contact and a contactless ignition device is whether or not there are any devices inside, such as a voltage converter, that have contact vibration. The DC-AC [15] contact ignition device with electromagnetic contact vibration has electromagnetic conversion abilities of vibration transformer coils, and low-voltage direct current becomes high-voltage pulse current. The diode then rectifies the signal and charges the energy-storing capacitance. When the capacitance voltage reaches the discharge tube's breakdown voltage, the discharge tube breaks down, releasing energy into the spark plug and cable. An electric spark is produced by the ignition spark plug. Then do it all over again. The operational life of a contact ignition device is shorter than that of a contactless ignition device due to the device's moving mechanical elements.

When the contactless ignition device is connected to a DC supply $[16,17]$, low-voltage DC power is converted to high-voltage AC power by filter circuit and DC converter circuit. It is rectified by time jitters of the diode and charges the energy-storing capacitance. When the voltage of the capacitance reaches the breakdown voltage of the discharge tube, the discharge tube breaks down. It discharges via the discharge tube and the spark plug generates an electric spark. The contactless ignition device is converted mainly by transistor devices.

1.2. Research Purpose. The ignition device, which is common in various aeroengines, is a control device that provides a rated voltage pulse for the combustion chamber in the aeroengine. In the aeroengine system, it is one of the most important control components. The ignition device ensures that the aeroengine system operates safely and reliably under a variety of external environmental conditions. A new type of revolutionary ignition device is a variable frequency and energy ignition device. Technology research on safe variable frequency and energy ignition device is underway in advance of the application needs for domestic aeroengines. The MCU and pulsed power key technologies are primarily used in its technology. It is a high-voltage pulsed power device that is required for concurrent hardware and software design jobs involving variable frequency and energy.

The purpose of this paper is to design a variable frequency and energy aeroengine ignition device [18]. Variable frequency and energy ignition technology is based on the traditional ignition system and is also advanced and intelligent. The big difference between the new system and the traditional system is the possession of abilities of variable frequency and energy. The core technology of the device is solid-state ignition technology. It uses semiconductor components instead of components such as contact transformer and gas discharge tube in traditional ignition technology. It has greatly improved. It has many advantages over traditional ignition device in electromagnetic compatibility, power adaptation, output stability, lifespan, reliability, and maintainability. In addition, variable frequency and energy ignition device adds control circuit based on solid-state ignition circuit to give control of frequency and energy. It can also provide a corresponding frequency electric spark for aeroengine in different climates.

A variable frequency and energy aeroengine ignition device can offer multiple combinations of frequency and energy [19]. The optimum ignition parameters can be progressively determined by matching with other engines under different operating conditions in the experiment. We can craft an ignition system limiting stored energy and a combustion chamber limiting ignition spark frequency by matching with each other from the minimum to the maximum. We determine the best composite value between stored energy and spark frequency under different operating conditions by carrying out experiments progressively. The ignition parameter under different engine operating conditions is given by further control logic. We can enhance start ignition reliability under different engine conditions effectively.

The function of variable frequency and energy is the leading technology in the ignition field, and the frequency and energy of traditional ignition are flat. When demand from customers changes, a new kind of device needs to be redesigned. It wastes time and cost. The variable frequency and energy ignition device designed in the paper has 75 kinds of combinations of frequency and energy. It is used more and more widely. That the aeroengine ignition device's ignition properties are set as a rule of thumb causes the waste of ignition device's resources, low efficiency of aeroengine's operation, and short service life of plugs. In this paper, a variable frequency and energy aeroengine ignition device is developed for improving the aeroengine combustion chamber's ignition function.

\section{Hardware Design}

The device uses MCU as the core controller. The MCU circuitry can simplify the control circuit and reduce the failure rate of the circuit. The principle block diagram of the ignition device designed in this paper is shown in Figure 1. The ignition device has a total of 15 kinds of frequency that 


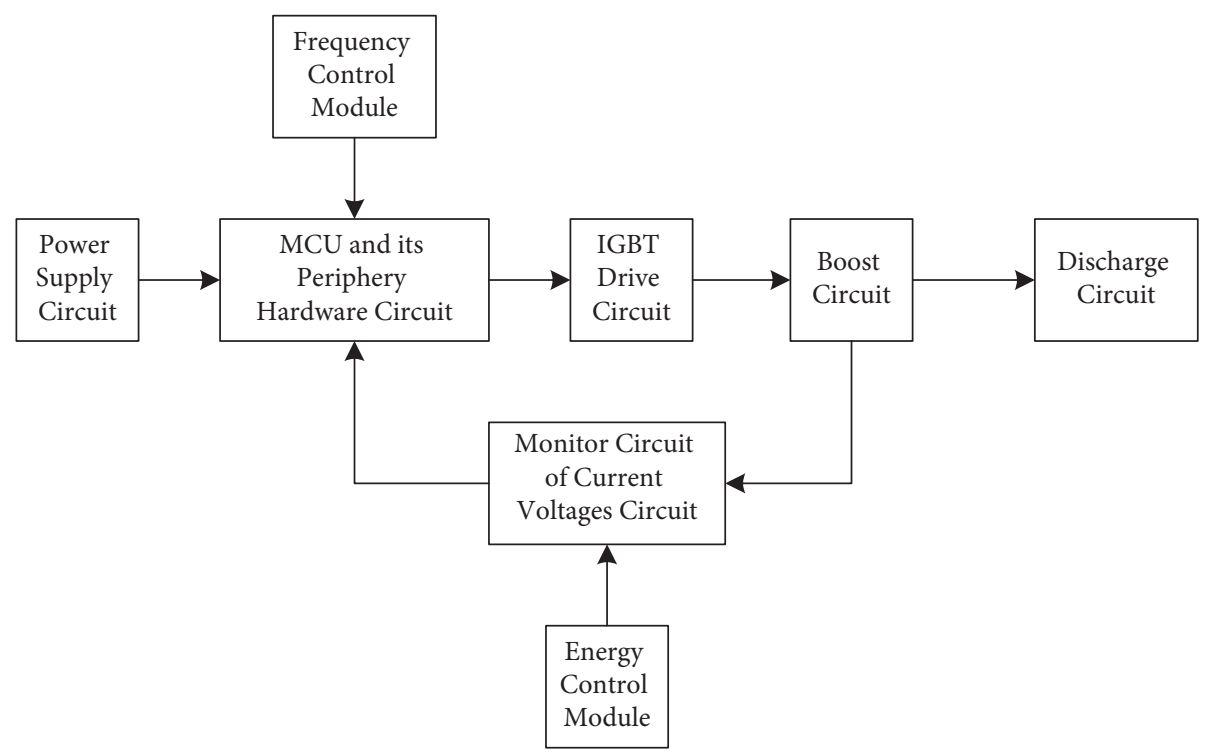

FIGURE 1: Block diagram of the variable frequency and energy ignition device.

ranges from $1 \mathrm{~Hz}$ to $15 \mathrm{~Hz}$ and 5 kinds of energy that ranges from $1 \mathrm{~J}$ to $5 \mathrm{~J}$.

The variable frequency and energy ignition device works as follows: power source $28 \mathrm{VDC}$ across the power circuit provides stable voltages of $+24 \mathrm{~V},+12 \mathrm{~V}$, and $+5 \mathrm{~V}$, which provides a stable and reliable power for various follow-up modules. The frequency control module causes MCU to output corresponding frequency PWM signals [20]. The signal is then amplified by the IGBT driver module to generate enough high driving voltage. The voltage drives boost circuit made up of IGBTs. Then the diode conducts and the energy-storing capacitance is charged up exponentially. The MCU detects the voltage across the energystoring capacitance by the monitor circuit of current-voltage circuit during charging. When the voltage is higher than the value set by the MCU, the MCU control ignition triggers port output high level, which triggers the discharge circuit. Then a steady stream of energy in the energy-storing capacitance is released by coil inductance, which breaks down the switch. At last, the ignition device realizes the ignition function. The frequency control module adjusts the frequency and the energy control module adjusts the energy.

2.1. Design of the Power Supply Circuit. The ignition device's input voltage is $28 \mathrm{VDC}$. The device adopts a 7800 series threeend integrate device that provides stable voltages of $+24 \mathrm{~V}$, $+12 \mathrm{~V}$, and $+5 \mathrm{~V}$ for follow-up circuits. Its circuit schematic is shown in Figure 2. We put the filter capacitors C1 C6 before the input of the circuit to remove clutter from the input. We put the vibration-proof capacitor C7 after the output of the circuit to remove clutter from the input. At last, stable voltages of $+24 \mathrm{~V},+12 \mathrm{~V}$, and $+5 \mathrm{~V}$ are obtained, respectively.

2.2. MCU and Its Peripheral Hardware Circuit. The STC89C52 MCU of 8051 series is chosen, which is powerful, port richly functional, cheap, and mainstream. The circuit is core to MCU STC89C52 and the switching circuit and A/D converter circuit are designed for its peripheral circuit. The switching circuit selects the silicon chip CD4076, which is one of the sixteen analog switches, in order to choose frequency that ranges from $1 \mathrm{~Hz}$ to $15 \mathrm{~Hz}$. The $\mathrm{A} / \mathrm{D}$ converter circuit selects $\mathrm{A} /$ D converter TLC2543 [21]. It digitizes voltages obtained by the monitor circuit of the current-voltage module. Then the result will be input to the MCU. In order to perform well, we should speed up the running rate of the MCU. So $11.0592 \mathrm{MHz}$ crystal is selected. Then the MCU can generate rectangle signals of corresponding frequency by its timer.

MCU hardware circuit is shown in Figure 3. Port P0.0 is the output interface of the PWM signal. Port P0.1 is voltage comparator circuit interface. Port P0.2 is ignition trigger interface. PWM-driven control adjusting theory is an operation that the power supply is opened and closed with some regular frequency. PWM is controlled by changing the length of switching power supply time. PWM frequency is changed by changing the timeframe in the ignition control system to generate PWM signal. So PWM is described as switch-driven device.

2.3. IGBT Drive Circuit. The maximum of the rectangle signal outputted by the MCU is $+5 \mathrm{~V}$, which is not sufficient to drive IGBT. So the IGBT drive circuit is needed. It can amplify the rectangle signal to some value which is enough to drive the IGBT. This module uses the silicon chip AST965 as the core controller. The amount of peripheral devices needed is minimal. And it is easy to operate. It can separate control circuits from functional circuits with minimal interference. The IGBT drive circuit is shown in Figure 4. The rectangle signal is input from port 1 and the amplified signal is output from port 8 .

2.4. Boost Circuit. The single-ended flyback construction is used in the boost circuit, as Figure 5 shows. A flyback transformer actually is a multiple winding coupling inductance. 


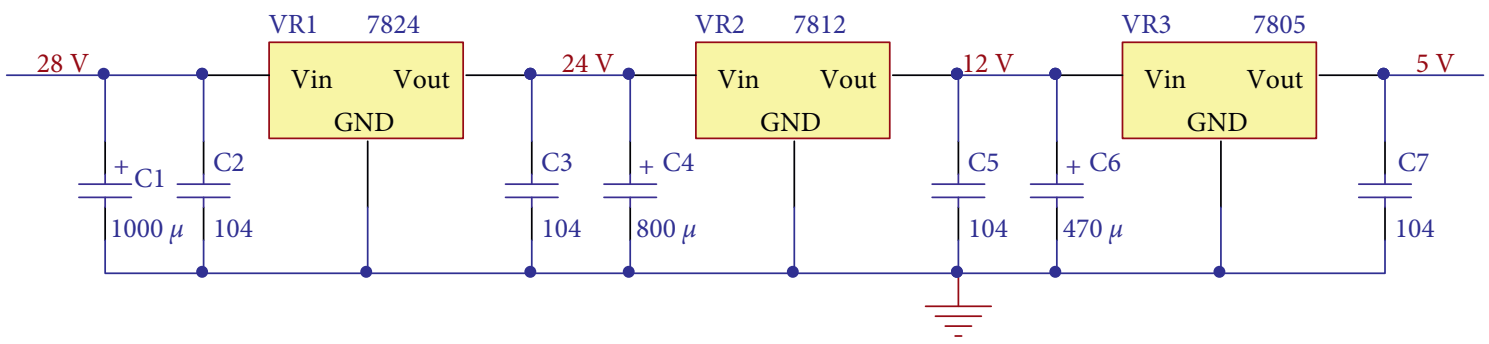

Figure 2: Power supply circuit.

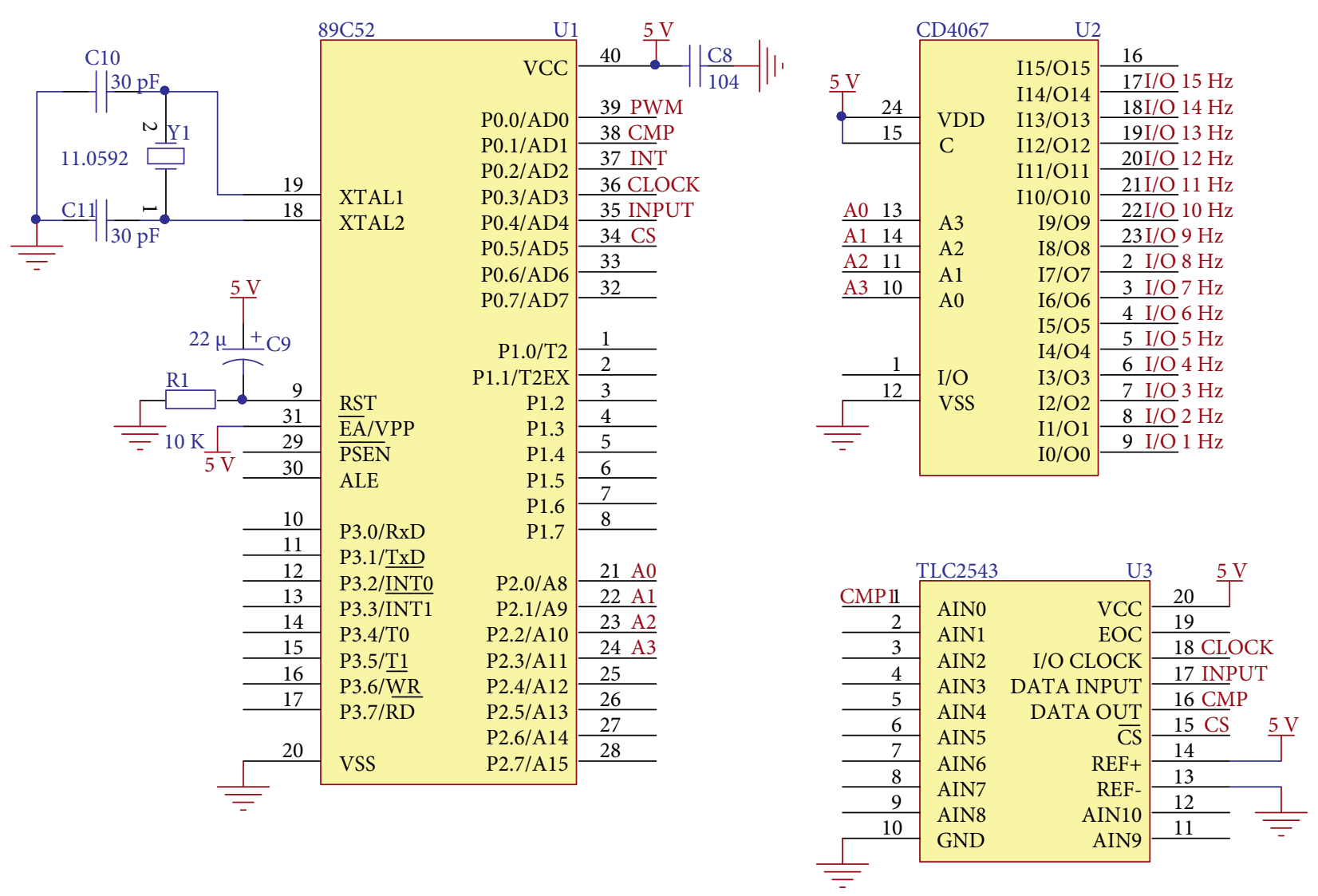

FIgURE 3: MCU and its peripheral hardware circuit.

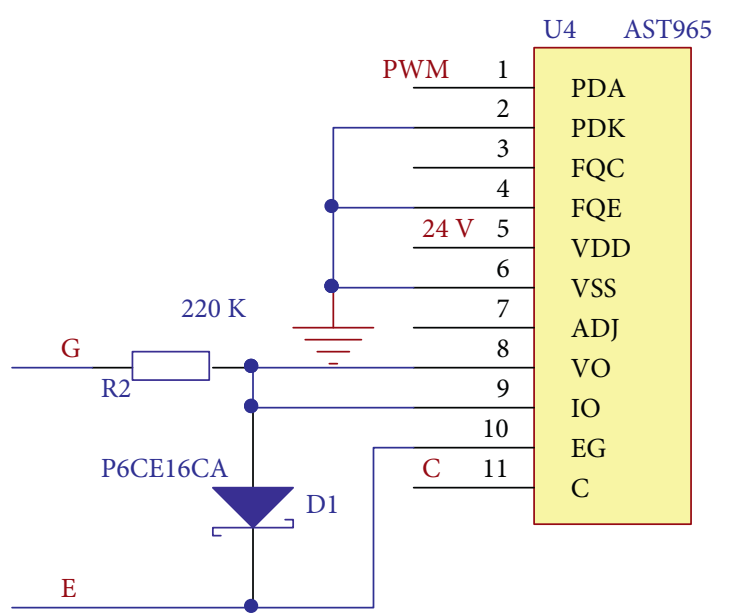

Figure 4: Drive circuit.
The flyback transformer stores energy and it transforms magnetic energy into electricity for transmission. When the IGBT is conducted, the diode is cut off and magnetic field energy is stored in the transformer T1 primary winding. When the IGBT is cut off, the voltage of the secondary winding breaks suddenly and induces a reverse voltage. Then the diode D3 conducts and magnetic field energy in the primary winding is released to the energy-storing capacitance.

During flyback conversion, the transformer has leakage inductance. Then both ends of the IGBT generate peak voltage that disturbs the circuit. So RDC absorbing circuit is designed in this module that inhibits peak voltage.

2.5. Monitor Circuit of Current-Voltage Circuit. The chief function is to monitor the voltage across the energy-storing capacitance. The voltage range of the MCU port is $0-5 \mathrm{~V}$. So 


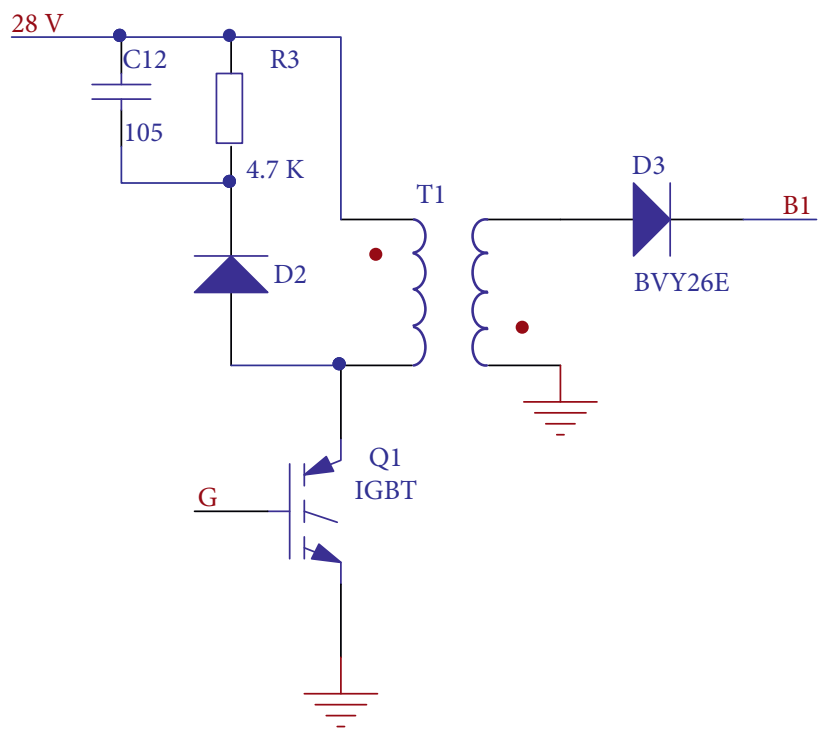

FIgURE 5: Boost circuit.

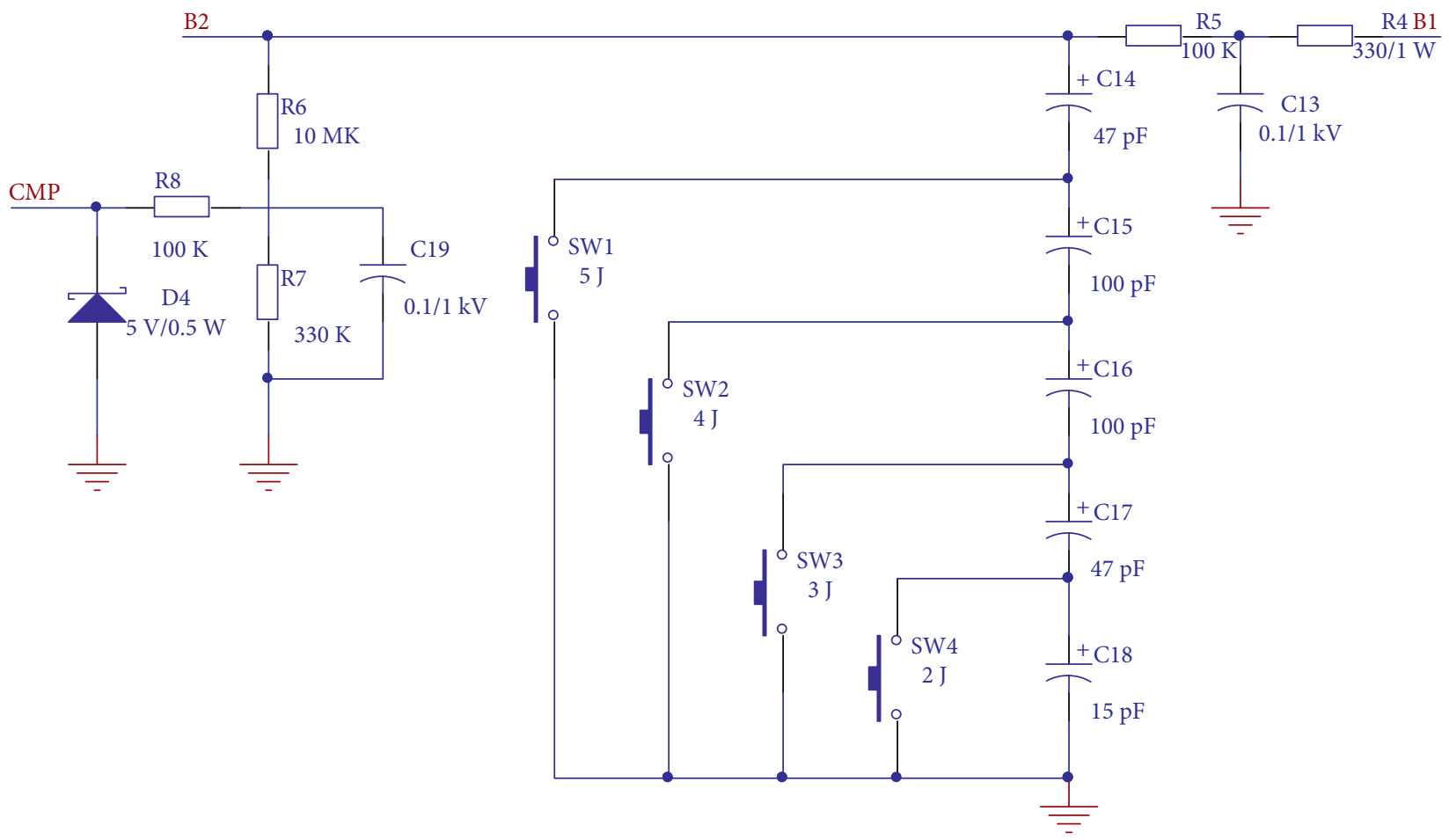

FIgURE 6: Monitor circuit of the current-voltage circuit.

collected voltage that is divided turns into a signal that can be recognized by the MCU. B1 is the input of the module, which is amplified by the boost module, as Figure 6 shows. It is filtered by the filter capacitor C13. Then it charges the energystoring capacitance. The voltage across the energy-storing capacitance is divided by the resistors R6 and R7. The voltage across the resistor is just the signal needed to collect. If it is higher than the values set by the MCU, the ignition trigger port outputs high-level signal. If it is lower than the values set by the MCU, the ignition trigger port outputs low-level signal.
Four switches are designed in the monitor circuit of the current-voltage circuit to realize the function of changing energy. C14 C18 are energy-storing capacitors. When no switches are pressed, the energy output of the device is $1 \mathrm{~J}$. When the switch SW1 is pressed, the energy output of the device is $2 \mathrm{~J}$. When the switch SW2 is pressed, the energy output of the device is $3 \mathrm{~J}$. When the switch SW3 is pressed, the energy output of the device is $4 \mathrm{~J}$. When the switch SW4 is pressed, the energy output of the device is $5 \mathrm{~J}$. 


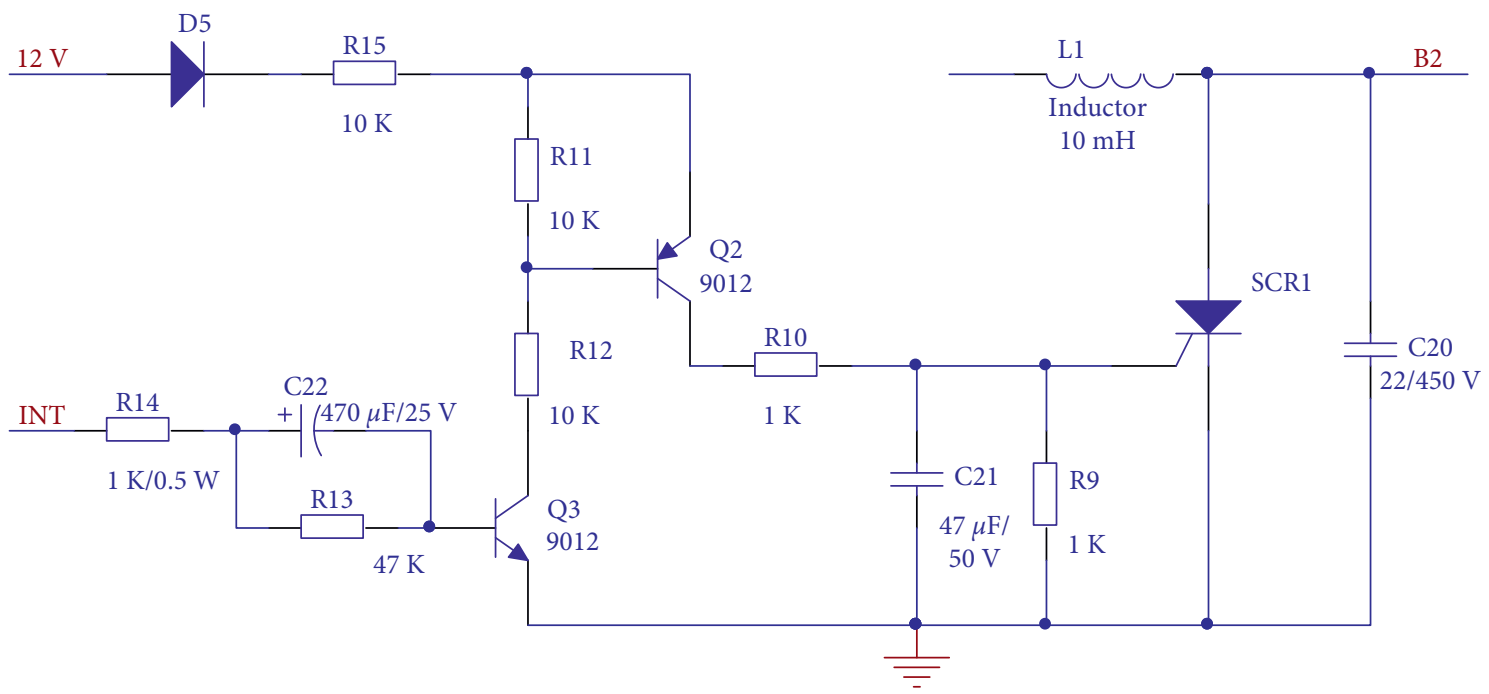

FIgURe 7: Discharge circuit.

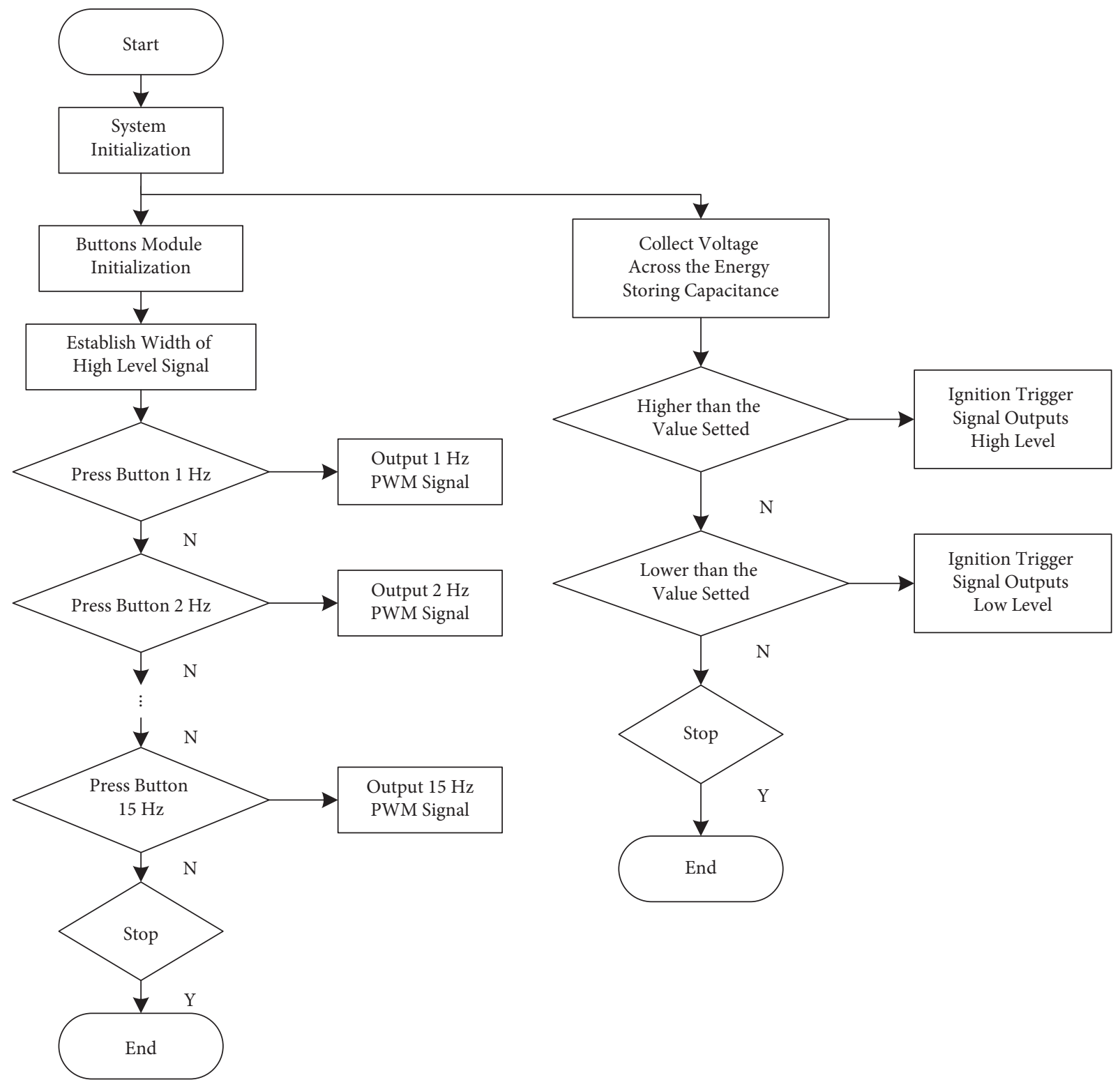

Figure 8: Software flow diagram. 
2.6. Discharge Circuit. While the energy-storing capacitance is fully charged, the energy in the capacitor needs to be released to the spark plug as soon as possible in order to realize the ignition function. The SCR is used as a switching device, as Figure 7 shows. When the PWM signal is high, potential differences between the base and emitter region of the triode Q3 are present. Then the triode Q3 conducts. Meanwhile, potential differences between the base and emitter region of the triode Q2 are also present. Then the triode Q2 conducts. At last, the SCR is triggered. As the energy-storing capacitance discharges continuously, the current between the anode and cathode of the SCR reduces gradually. Then the SCR is cut off, and the discharge process of the energy-storing capacitance can be accomplished.

\section{Software Design}

This section introduces MCU code, which is divided between PWM signal generating and trigger discharging section. The code is downloaded in the MCU through the software Keil uVision [22]. The principal program flow is shown in Figure 8.

The following are the chief functions of the software design:

(1) The software makes port $\mathrm{P} 0.0$ of the MCU generate a PWM driving signal.

(2) The software makes the MCU generate a trigger signal. Port P0.1 of the MCU is the comparing port and port $\mathrm{P} 0.1$ is the ignition trigger port. When the voltage collected by the monitor circuit of the current-voltage circuit is higher than values set by the MCU, port P2.0 outputs high-level signal. When it is lower than values set by the MCU, port P2.0 outputs low-level signal.

(3) The software control frequency of the PWM signal is outputted by the MCU. The MCU controls frequency by code switches. The range of frequency is from $1 \mathrm{~Hz}$ to $15 \mathrm{~Hz}$.

\section{Conclusion}

In this paper, a variable frequency and energy aeroengine ignition device is designed. It controls the frequency that ranges from $1 \mathrm{~Hz}$ to $15 \mathrm{~Hz}$ and energy that ranges from $1 \mathrm{~J}$ to $5 \mathrm{~J}$. There are 75 kinds of permutations of frequency and energy. The device lays the foundations for the study of the combustion chamber's ignition property and the realization of maximizing the combustion chamber's lean ignition excess air coefficient and shortening ignition lag time. We can adjust the ignition abilities of ignition devices according to engine performance to make the engine reduce power consumption and lighten the flighting burden. I think that there will be a breakthrough in the number range of energy of ignition devices by software in the future. I should research on how to decrease the volume of the device. How to enhance the reliability and electromagnetic compatibility features of ignition devices deserves further investigation.

\section{Data Availability}

The data used to support the findings of this study are available from the author upon request.

\section{Conflicts of Interest}

The author does not have any possible conflicts of interest.

\section{References}

[1] Y. C. Hsieh, M. R. Chen, and H. L. Cheng, "An interleaved flyback converter featured with zero-voltage transition," IEEE Transactions on Power Electronics, vol. 26, no. 1, pp. 79-84, 2010.

[2] S. L. Brockveld and G. Waltrich, "Boost-flyback converter with interleaved input current and output voltage series connection," IET Power Electronics, vol. 11, no. 8, pp. 1463-1471, 2018.

[3] M. T. Zhang, M. M. Jovanovic, and F. C. Y. Lee, "Design considerations and performance evaluations of synchronous rectification in flyback converters," IEEE Transactions on Power Electronics, vol. 13, no. 3, pp. 538-546, 1998.

[4] S. Dusmez, M. Bhardwaj, L. Sun, and B. Akin, "In situ condition monitoring of high-voltage discrete power MOSFET in boost converter through software frequency response analysis," IEEE Transactions on Industrial Electronics, vol. 63, no. 12, pp. 7693-7702, 2016.

[5] J. Jun Wang, X. Xiaohu Zhou, J. Jun Li et al., "10-kV SiC MOSFET-based boost converter," IEEE Transactions on Industry Applications, vol. 45, no. 6, pp. 2056-2063, 2009.

[6] J. Wang, J. Li, X. Zhou et al., "10 kV SiC MOSFET based boost converter," in Proceedings of the 2008 IEEE Industry Applications Society Annual Meeting, pp. 1-6, Edmonton, Alberta, Canada, 2008 October.

[7] E. Rokicki, R. Przysowa, J. Kotkowski, and P. Majewski, "High temperature magnetic sensors for the hot section of aeroengines," Aerospace, vol. 8, no. 9, Article ID 261, 2021.

[8] H. Weng, F. L. Duan, Z. Ji et al., "Electrical insulation improvements of ceramic coating for high temperature sensors embedded on aeroengine turbine blade," Ceramics International, vol. 46, no. 3, pp. 3600-3605, 2020.

[9] G. Schaefer, M. Kristiansen, and A. H. Guenther, Eds., Gas Discharge Closing Switches, Springer Science and Business Media, Berlin/Heidelberg, Germany, 2013.

[10] G. A. Mesyats, "Electron-triggered gas-discharge switches," Pulsed Power, pp. 307-322, 2005.

[11] Y. Lin, Y. Jun, and Z. Cheng, "Research on performance optimization strategy of solar semiconductor refrigeration system based on boost circuit," in Proceedings of the 2020 5th International Conference on Electromechanical Control Technology and Transportation (ICECTT), pp. 1-5, Nanchang, China, 2020 May.

[12] C. Poggiani, M. Battistoni, C. N. Grimaldi, and A. Magherini, "Experimental characterization of a multiple spark ignition system," Energy Procedia, vol. 82, pp. 89-95, 2015.

[13] T. Alger, J. Gingrich, C. Roberts, B. Mangold, and M. Sellnau, "A high-energy continuous discharge ignition system for dilute engine applications," SAE Technical Paper, vol. 8, no. 4, Article ID 2013-01-1628, 2013.

[14] P. Vidaud, S. M. A. Durrani, and D. R. Hall, "Alpha and gamma RF capacitance discharges in N2at intermediate pressures," Journal of Physics D: Applied Physics, vol. 21, no. 1, pp. 57-66, 1988. 
[15] P. Forgács, J. Feketü, and M. Horváth, "Power stages and microcontroller based timing of a multi-function power converter for welding," in Proceedings of the IEEE International Symposium on Industrial Electronics, pp. 813-819, Gdansk, Poland, 2011 June.

[16] V. F. Pires, A. Cordeiro, D. Foito, and J. F. A. Silva, "Dual output and high voltage gain DC-DC converter for PV and fuel cell generators connected to DC bipolar microgrids," IEEE Access, vol. 9, pp. 157124-157133, 2021.

[17] T. Yamamoto, J. Rikitake, S. Matsumoto, T. Ninomiya, and S. Abe, "A new control strategy for power supply on chip using parallel connected DC-DC converters," in Proceedings of the IEEE 10th International Conference on Power Electronics and Drive Systems (PEDS), pp. 109-112, Kitakyushu, Japan, 2013 April.

[18] Y. Che, B. Feng, and J. Bian, "A steady-frequency high-energy aero engine ignition unit," Applied Science and Technology, vol. 5, 2015.

[19] Q. He, C. Dong, K. Li, J. Wang, D. Xu, and X. Li, "A multiple energy-harvester combination for pattern-recognizable power-free wireless sensing to vibration event," Sensors and Actuators A: Physical, vol. 279, pp. 229-239, 2018.

[20] M. Jordan, H. Langkowski, T. Do Thanh, and D. Schulz, "Frequency dependent grid-impedance determination with pulse-width-modulation-signals," in Proceedings of the 2011 7th International Conference-Workshop Compatibility and Power Electronics (CPE), pp. 131-136, Tallinn, Estonia, 2011 June.

[21] H. J. Yang, J. H. Liu, and S. Q. Ma, "The low frequency virtual oscilloscope based on TLC2543 and VB," Journal of Northwest Normal University, vol. 2, 2007.

[22] H. Saidi, M. Turki, Z. Marrakchi, M. Abid, and A. Obeid, "Soft-core embedded FPGA based system on chip," Analog Integrated Circuits and Signal Processing, vol. 109, no. 3, pp. 517-533, 2021. 